\title{
Dos cartas de Mariana y García de Loaysa: Del gobierno civil al eclesiástico y otras notas intelectuales
}

\author{
Fernando CENTENERA SÁNCHEZ-SECO \\ Universidad de Alcalá
}

\begin{abstract}
RESUMEN
En este trabajo se analiza el contenido de dos manuscritos Egerton. Estos manuscritos forman parte de la correspondencia entre Mariana y García de Loaysa en 1598. Según la interpretación que se ofrece en este trabajo, los textos de los documentos dan noticia de algunas recomendaciones del jesuita para el gobierno episcopal de su amigo. En su discurso es posible ver interesantes parecidos con algunas de las ideas que propone a propósito del gobierno civil. Además, los textos que se estudian descubren varias inquietudes intelectuales y profundos afectos personales.
\end{abstract}

PALABRAS CLAVE: Mariana, García de Loaysa, gobierno

\begin{abstract}
This study analyses the contents of two Egerton manuscripts. These manuscripts are part of the correspondence of 1598 between Mariana and García de Loaysa. This study interprets the texts of these documents as recording some of the Jesuit's recommendations concerning the episcopal governance of his friend. Together, the texts offer several points of resemblance with Mariana's ideas about civil government. They also reveal various intellectual concerns and the depth of his personal relations.
\end{abstract}

KEYWORDS: Mariana, García de Loaysa, governance

\section{Introducción}

En el prólogo de la obra De rege et regis institutione Mariana escribe lo siguiente: «Allí, como de ordinario acontece, nos acordamos de las últimas cartas recibidas, e hicimos naturalmente mención, oh príncipe, de tus sabios maestros el marqués de la Velada y García de Loaysa, hombres eminentes de los que quedan pocos en nuestros tiempos, de singular sencillez en sus costumbres, de gran amabilidad y prudencia, que conservan aún toda la gravedad de nuestros antiguos nobles» ${ }^{1}$. La referencia a García de Loaysa en este lugar no es gratuita, dado que como también afirma el jesuita en el mismo prólogo, fue precisamente él quien le invitó a que contribuyera a la educación del príncipe con el trabajo mencionado ${ }^{2}$. Estas noticias ponen de manifiesto la estrecha amistad entre Mariana y García de Loaysa. Pero además de ellas, contamos también con otros documentos que, aunque menos conocidos y estudiados, corroboran aquella estrecha relación y aportan datos interesantes a propósito de los pormenores de la misma. Este

${ }^{1}$ J. De Mariana, La dignidad realy la educación del rey, Madrid, Centro de Estudios Constitucionales, 1981, 7.

2 Ibidem, 13.

[Recibido: 11-11-2014/ Aceptado: 01-07-2015]

http://dx.doi.org/10.5209/rev_INGE.2015.v9.51540 
estudio está dedicado al análisis de algunos de estos documentos. No obstante, antes de presentarlos con más detenimiento, y con el fin de contextualizarlos adecuadamente, pensamos que conviene mencionar algunas notas generales sobre García de Loaysa.

García de Loaysa nació en Talavera de la Reina en el seno de una familia noble. Según el propio Mariana, era de condición muy apacible, alto y de rostro agradable 3 . Fueron numerosos los cargos que desempeñó: formó parte del cabildo catedralicio toledano ${ }^{4}$, fue capellán mayor, limosnero real, miembro del Consejo de la Inquisición ${ }^{5}$ y maestro del futuro Felipe III $^{6}$ (de ahí, la solicitud que dirigió a Mariana para que escribiese un libro sobre la educación real). Su carrera eclesiástica, no obstante, no se agota con los datos anteriores. Después de que Alberto de Austria renunciase al arzobispado para casarse con Isabel, la hija de Felipe II, el papa Clemente VIII nombró a García de Loaysa arzobispo de Toledo. Fue el 8 de julio de 15987. La consagración se llevó a cabo por el nuncio apostólico y tuvo lugar en el monasterio del Escorial, el 16 de agosto ${ }^{8}$. Sin embargo, el arzobispo no quiso entrar en Toledo ni en su iglesia, si no era con el palio arzobispal. Al parecer, aquel llegaba de Roma con retraso y, entre tanto, García de Loaysa decidió dejar pasar el tiempo en Alcalá de Henares ${ }^{9}$. La marcha hacia la ciudad complutense en la que, por cierto, se había formado tiempo atrás, se fecha en enero de $1599^{10}$. El arzobispo, sin embargo, nunca llegó a entrar en Toledo, pues murió en Alcalá de Henares en febrero de 1599.

En los meses que transcurren desde el nombramiento del arzobispo en adelante, aquel mantuvo correspondencia con Mariana. En este trabajo se analizan dos cartas, una del jesuita y otra del arzobispo con la que respondió a la primera. Se trata de unos manuscritos que Mariana dejó tras su muerte, junto con otros muchos, en el Colegio de

\footnotetext{
3 J. De Mariana, «Historia general de España», en Obras del Padre Juan de Mariana, t. II, Madrid, M. Rivadeneyra, 1854, 408.

${ }^{4}$ F. DE PISA, Apuntamientos para la II parte de la "descripción de la imperial civdad de Toledo", Toledo, Diputación Provincial de Toledo, 1976, 39, nota a pie de página 'a' del cardenal Lorenzana.

${ }^{5}$ Sobre estos datos F. DE PISA, Descripción de la imperial civdad de Toledo, Toledo, Pedro Rodríguez, 1605 (edición facsímil de 1974), 271; A. FERNÁNDEZ COLLADO, La catedral de Toledo en el siglo XVI. Vida, arte y personas, Toledo, Diputación Provincial de Toledo, 1999, 255.

${ }^{6} \mathrm{~J}$. DE MARIANA, «Historia general de España», 407.

7 A. FERNÁNDEZ COLLADO, La catedral de Toledo..., 255.

${ }^{8}$ F. DE PISA, Descripción..., 271; A. FERnÁNDEZ COlLAdo, La catedral de Toledo..., 255.

${ }^{9}$ F. DE PISA, Descripción..., 273.

10 A. FERnÁNDEZ Collado, La catedral de Toledo..., 256.
} 
la Compañía de Jesús de Toledo, donde vivió gran parte de su vida. Después de numerosas transacciones, aquella documentación pasaría a formar parte de la British Library. Hoy se encuentra catalogada en la colección de manuscritos Egerton. Concretamente los manuscritos que nos interesan están en la signatura Egerton 187511, número 19, si seguimos la enumeración que utilizó Gayangos a la hora de catalogar los documentos en 1875. El título en el que se enmarcan es el siguiente ${ }^{12}$ : 19 . Various letters of Garcia de Loaysa [Giron], archbishop of Toledo, to Fath. Mariana, with the latter's answers. Dat. Jul.-Nov. 1598, holog.». Los manuscritos están paginados, van de la página 77 a la 80. Pensamos, no obstante, que la paginación se realizó posteriormente.

Como hace notar Gayangos en el texto citado in fine, se trata de documentos escritos por el propio jesuita y por García de Loaysa. Son una muestra más de la amistad que tenían, aunque especialmente representativa y particular, teniendo en cuenta el momento en el que se escribieron. Los textos de los manuscritos descubren cuestiones relativas al gobierno eclesiástico que estaba iniciando García de Loaysa. Con ellas, en nuestra opinión, se extrapolan de algún modo al ámbito eclesiástico varios aspectos de filosofía política, que el jesuita había pensado para el gobierno civil. Además, la correspondencia deja testimonio de varias inquietudes intelectuales y personales que, en definitiva, reflejan el espíritu de una época. En este estudio ofrecemos numerosos análisis sobre todas estas cuestiones, seguidos de la transcripción de los textos. Esta no es la primera vez que se transcriben los manuscritos. Pueden encontrarse en un estudio preliminar de una edición de la Historia General de España de 1783, llevado a cabo por Nogueira ${ }^{13}$ (según pensamos, este autor debió consultar los manuscritos cuando todavía estaban en el Colegio de la Compañía, si bien ya habría tenido lugar la expulsión de la Orden $\left.{ }^{14}\right)$. Pensamos, no obstante, que es posible ofrecer una versión de los documentos

\footnotetext{
${ }^{11}$ Sobre estas cuestiones F. CENTENERA SÁNCHEZ-SECO, «De Toledo a Londres: El último viaje de Juan de Mariana», Cabeza encantada Humanism e-review, 1 (2011), 1-28. Consultado en http://www.proyectos.cchs.csic.es/humanismoyhumanistas/sites/proyectos.cchs.csic.es.humanismoyhu manistas/files/CENTENERA\%20DE\%20TOLEDO \%20A\%20LONDRES\%282\%29 0.pdf. Fecha de consulta: $02 / 11 / 2014$.

${ }^{12}$ P. De Gayangos, Catalogue of the Manuscripts in the Spanish Language in the British Library, vol. I, Great Britain, The British Library, reprinted, 1976, 198.

13 A. Nogueira, «Historia de la vida y escritos del P. Juan de Mariana», en J. De Mariana, Historia General de España, tomo I, Valencia, Oficina de Benito Monfort, MDCCLXXXIII, XCVII y XCVIII.

${ }^{14}$ Tiempo después de que saliera su estudio anexo a la edición de la Historia General de España, adquiriría el material el mercader Juan Rodríguez de Vigo. Así cabe entenderse de una interpretación que hace Cirot a
} 
más cercana a los originales. Teniendo en cuenta este objetivo, hemos llevado a cabo la transcripción siguiendo las siguientes pautas: la grafía original se respeta aunque sea defectuosa, en la separación de las palabras se ha seguido el documento original, las letras dobles se respetan, las palabras abreviadas se respetan y se desarrollan en nota a pie de página, si no hay seguridad en relación a la transcripción de una palabra o expresión se pone entre corchetes ([...]). En relación a esta última cuestión, y como podrá observarse en su momento puntualmente, hemos tenido en cuenta el trabajo de Nogueira.

\section{Consejos para un buen gobierno}

Como ya se ha dicho, García de Loaysa fue nombrado arzobispo de Toledo el 8 de julio de 1598. Probablemente se trataba del momento más importante en su vida como eclesiástico. La responsabilidad del cargo así lo confirma. Desde su sede, el arzobispo de Toledo regía una archidiócesis que comprendía casi todo el centro de España. Su jurisdicción incluía doscientas ochenta y siete villas (entre ellas Madrid) y se ejercía sobre ocho obispos sufragáneos. Era además primado de España, un título que, si bien tenía carácter honorífico, convertía al arzobispo en portavoz oficial de la Iglesia española15. Según parece, Mariana debió tener noticia del nombramiento antes de que aquel tuviese lugar de forma oficial. En la carta que nos va a ocupar en este espacio, fechada el 7 de julio de 1598, refiriéndose a "esta election" el jesuita le felicita por su nuevo estatus. Según Nogueira, la enhorabuena a García de Loaysa se presenta colateralmente, a modo de 'accidente' al final de la carta, dado que el asunto principal que contempla es el relativo a un criado $^{16}$, al que nos referiremos más adelante. En nuestra opinión, no obstante, el reconocimiento de la nueva situación tiene un protagonismo indudable a lo largo todo del documento. Ello se percibe desde el punto de vista del contenido, como veremos a lo largo de este apartado, pero también desde la perspectiva formal. Desde el comienzo de la carta y en repetidas veces a lo largo de la misma, Mariana se refiere a García de Loaysa con el tratamiento de "V.S.I." que, pensamos, ha de entenderse como Vuestra Señoría Ilustrísima. Si seguimos lo que se dice en los Titres Qu'on doit donner à chaque sorte de personnes, de bouche ou par écrit, selon leur qualité \& profesión, trabajo anexo a los Diálogos nuevos

partir de una declaración que recogen los manuscritos Egerton 1869. G. CIROT, Mariana Historien, Bordeaux, Feret \& Fils Éditeurs, 1905, 394 y 395.

${ }^{15}$ R. L. KAGAN, «La Toledo del Greco», en El Greco de Toledo, Madrid, Alianza Editorial, 1982, 53.

16 A. NogueIRA, «Historia de la vida...», LV. 
de Francisco Sobrino, el tratamiento en cuestión se utilizaba cuando el receptor era un obispo o arzobispo ${ }^{17}$. Cabría entender, por tanto, que casi desde el comienzo del texto, el jesuita está reconociendo la nueva condición de su amigo, aun cuando deja la felicitación explícita para la última parte de su discurso. No obstante, aun siendo la interpretación anterior acertada, conviene reparar en el detalle de que en este documento Mariana no comienza diciendo "Ilustrísimo Señor" (en la parte superior del papel y justificado al centro), que es el tratamiento con el que se tenía que empezar una carta dirigida a un arzobispo, si seguimos la fuente relativa a los títulos antes mencionada ${ }^{18}$. A propósito de este detalle, es interesante señalar que en otra carta posterior que el jesuita remitiría a García de Loaysa, y cuyo estudio dejaremos para otra ocasión, las reglas mencionadas sí que se siguen.

A propósito de la cuestión de la elección, Mariana se refiere también a las desavenencias que debió causar en algunos sectores. El jesuita informa a García de Loaysa de que el acontecimiento no se había tomado en todo caso de la misma manera; aunque achaca estas manifestaciones a la envidia y al pesar que a algunas personas debió causar el hecho de que su amigo llegase tan lejos. A propósito de estas cuestiones, debe tenerse en cuenta que el ascenso de García de Loaysa debió representar una amenaza para determinados intereses. Antes de su marcha a Flandes y después de recibir el nombramiento de gobernador de aquel lugar por Felipe II (1596), Alberto de Austria, arzobispo de Toledo, nombró a García de Loaysa gobernador eclesiástico de la archidiócesis de Toledo ${ }^{19}$. Ya entonces, el gobernador jugó un papel importante en la activación de la reforma eclesiástica. Sin embargo, en esta labor encontró la resistencia del cabildo, de vicarios generales y foráneos, visitadores, arciprestes, e incluso del mismo Consejo de la Gobernación ${ }^{20}$. Según parece, detrás de estas desavenencias parece que habría que ver tensiones por la conservación del poder. La labor que debía llevarse a cabo era poner en

\footnotetext{
${ }^{17}$ F. SOBRINO, Titres Qu'on donner à chaque sorte de personnes, de bouche ou par écrit, selon leur qualité \& profession, en D. M. Sáez Rivera (ed.), «Diálogos Nuevos (Anexos) de Francisco Sobrino (1708)», LEMIR. Revista Electrónica sobre Literatura Española Medieval y Renacimiento, apartado de anexos, 325. Consultado en http://parnaseo.uv.es/Lemir/Textos/Sobrino/Anexos.pdf. Fecha de consulta: 02/11/2014.

${ }^{18}$ F. SOBRINO, Titres Qu'on donner, 325.

${ }^{19}$ F. De Pisa, Descripción..., 271; A. Fernández Collado, A., La catedral de Toledo..., 252, 255.

${ }^{20}$ M. GutiÉRrez García-BrazAles, «El consejo de la Gobernación del Arzobispado de Toledo», Anales Toledanos, 16 (1983), 75 y 76. Consultado en: http://www.realacademiatoledo.es/files/ anales/0016/03.pdf. Fecha de consulta: 02/11/2014.
} 
claro las competencias de todos aquellos cargos, sometiéndolos a la autoridad episcopal. En un contexto eclesiástico caracterizado por la relajación, García de Loaysa iba a aplicar los decretos disciplinares del Concilio de Trento y a reformar sus costumbres. De este modo aparecieron sus Instrucciones, para poner fin a los abusos de autoridad o las intromisiones recíprocas ${ }^{21}$. Lo cierto es que el Consejo no se resignó fácilmente a las solicitudes del gobernador. Lo que se pretendía, en definitiva, era disminuir el poder de García de Loaysa ${ }^{22}$. Las tensiones debieron seguir en los años siguientes, dado que después de su consagración, el arzobispo publicó otras Instituciones donde se establecían límites a las vicarías ${ }^{23}$. Por otra parte, aunque desde una perspectiva más alejada, habría que hacer referencia también a otras tensiones entre la Nunciatura y el Consejo de Gobernación y a la oposición que mostraba el Consejo Real frente al del arzobispado, que incluso apuntaba a su supresión ${ }^{24}$.

Como decíamos, al menos en parte, en aquellas tensiones debió estar presente la pretensión de restar poder al arzobispo. Precisamente tal circunstancia pudo haber sido el fundamento de las palabras críticas de Mariana para con quienes manifestaron sus reticencias con el nuevo arzobispado. Esta reflexión tiene consonancia con el parecer del jesuita en relación a la mejor forma de gobierno. Como es sabido, era partidario de una monarquía en el ámbito civil25, una decisión que le hizo ser crítico con los poderes señoriales de los últimos años de la Edad Media, causantes de numerosas tensiones con el poder regio ${ }^{26}$. Quizá pudiera pensarse que este planteamiento se desarrolla en el contexto civil, y que por tanto no es asimilable al que nos ocupa. Sin embargo, no parece haber especial problema con extrapolar esta opinión del jesuita al ámbito del gobierno eclesiástico. En este sentido, puede ser interesante recordar que a propósito de un contexto eclesiástico concreto Mariana escribió algunos años después, a comienzos del

\footnotetext{
${ }^{21}$ Ibidem, 76.

22 Ibidem, 77.

23 Ibidem, 80.

${ }^{24}$ M. GutiérRez GarcíA-Brazales, «El consejo de la Gobernación del Arzobispado de Toledo (2a parte)», Anales Toledanos, 25 (1988), 129, 130. Consultado en: http://www.realacademiatoledo.es/ files/anales/0025/07.pdf. Fecha de consulta: 02/11/2014.

${ }^{25} \mathrm{~J}$. De MARIANA, La dignidad..., 7.

26 Puede verse un estudio sobre un contexto concreto en F. CENTENERA SÁNCHEZ-SECO, «El poder local en el pensamiento filosófico-político de Juan de Mariana: Algunas consideraciones acerca del derecho de resistencia en el caso de Fuenteovejuna», en M. Campillo Méndez y J. J. Ruiz Ibáñez (eds.), Felipe II y Almazarrón: La construcción local de un Imperio global. Sostener, gobernar y pensar la frontera, Murcia, Universidad de Murcia, 2014, 398, 399.
} 
siglo XVII, el Discurso de las cosas de la Compañía. En esta obra el jesuita vuelve a referirse a la monarquía como la mejor forma de gobierno ${ }^{27}$, y parece criticar ciertas intromisiones procedentes de Roma ${ }^{28}$.

Quizá pudiera pensarse que la preferencia del jesuita a la que nos acabamos de referir se enfrenta a la existencia de un consejo y que por ello habría que entender que el religioso debió ser crítico con el Consejo de la Gobernación. A nuestro juicio, sin embargo, esta conclusión es demasiado precipitada. Lejos de presentar un obstáculo, para Mariana el consejo es necesario para que la forma de gobierno ideal (la monarquía) sea aún más preferible. Ello, de nuevo, tanto en lo que respecta a la perspectiva civil ${ }^{29}$, como a la eclesiástica ${ }^{30}$. Si tenemos todo ello en cuenta, cabría pensar que el jesuita habría estado en desacuerdo, no ya con el consejo en sí, sino con las concesiones de poder que había ido adquiriendo la institución; algo que no parece ajustarse a la idea de Mariana de que la ejecución ha de ser de una persona, aun cuando detrás convenga contar con el consejo de muchas $^{31}$. Sin embargo, pensamos que este planteamiento debe reconsiderarse. Aun cuando en los inicios del consejo del arzobispado pudieran verse parecidos con los consejos reales ${ }^{32}$, conviene señalar que con el tiempo aquel adquirió determinadas especificidades; llegando a ser un órgano colegiado con facultades delegadas por el obispo ${ }^{33}$. Teniendo esto en cuenta, sería más preciso decir que en el caso de que pudiese percibirse una crítica del jesuita hacia la institución que nos ocupa, aquella versaría, no ya sobre las cotas de poder asumido (que probablemente deberían entenderse como ineludibles, a consecuencia de las dimensiones del arzobispado), sino sobre las extralimitaciones e intromisiones -que existieron- llevadas a cabo en relación al propio poder y al del arzobispo, respectivamente.

Siguiendo con la noticia de la elección, Mariana no duda en referirse al futuro del gobierno del prelado, augurando que sería una experiencia ejemplar en muchos años. Lo cierto es que no es de extrañar la complacencia con la que Mariana trata el

${ }^{27}$ J. De Mariana, «Discurso de las cosas de la Compañía», en Obras del Padre Juan de Mariana, t. 31, B.A.E., Madrid, Atlas, 1950, 605.

${ }^{28}$ Sobre la cuestión F. CENTENERA SÁNCHEZ-SECO, El tiranicidio en los escritos de Juan de Mariana, Madrid, Dykinson, 2009, 136, 350.

${ }^{29}$ J. DE MARIANA, La dignidad..., 37.

${ }^{30} \mathrm{~J}$. DE MARIANA, «Discurso...., 605.

31 Ibidem.

32 M. GutiérRez García-BraZALes, «El consejo de la Gobernación...», 67.

${ }^{33}$ Ibidem, 71. 
acontecimiento. A propósito de la elección de los obispos, en su obra De rege et regis institutione considera que han de escogerse para estos cargos a hombres de reconocida prudencia y probidad, maduros y, a ser posible, que hayan dedicado su vida anterior a las funciones eclesiásticas. De este modo, continúa el jesuita, no resulta acertado que se hagan pastores del rebaño a hombres profanos. Si se ha de elegir entre teólogos o jurisconsultos en una situación de igualdad, deberán ser preferidos los primeros para los cargos eclesiásticos ${ }^{34}$. Sin duda, la figura de García de Loaysa debía ser el reflejo práctico de estos consejos en los que, por cierto, si bien se observa el requerimiento de tener estrecha relación con cuestiones eclesiásticas, también se recoge la cuestión de la prudencia; un aspecto que avalaba a García de Loaysa como tutor del rey ${ }^{35}$, que ya aparece en el pensamiento de Maquiavelo, y que se encuentra conectado, no ya con la ética, sino con la eficacia en cuestiones políticas ${ }^{36}$. Como veremos en breve, este detalle encuentra reflejo en determinadas propuestas del jesuita.

Sin embargo, y aun cuando las felicitaciones y apoyos constituyen una noticia relevante de la carta, Mariana comienza aquella refiriéndose a una cuestión más concreta que ya adelantamos (la misma, no obstante, entendemos que se contextualiza en la temática que venimos desarrollando). En las primeras líneas del documento el jesuita constata que un sacerdote, el padre Sebastián, le había escrito a propósito de un criado de García de Loaysa (y, al parecer, de su parte), que había llevado una conducta reprochable. Según la interpretación que hacemos del texto, se trata de una conversación de la que se había derivado escándalo. Parece que lo que se requería de Mariana es que mediase en este conflicto para resolver la cuestión, y a juzgar por el texto parece que así lo hizo, aunque según su testimonio el criado debió negar los hechos y acusar a otras personas. En cualquier caso, parece que el jesuita le concedió el beneficio de la duda. Sin embargo, en las palabras de Mariana pensamos que debería verse algo más.

Más allá del caso concreto que, como decimos, según el criterio del jesuita parece que todavía tendría remedio, resulta especialmente significativo el hecho de que a continuación de todo aquello, Mariana ofrezca a García de Loaysa el siguiente consejo: «Y es aueriguado que tal sera el gouierno de un prelado quales fueren sus ministros y

\footnotetext{
${ }^{34}$ J. De MARIANA, La dignidad..., 278 y 279.

${ }^{35}$ H. E. Braun, Juan de Mariana and Early Modern Spanish Political Thought, England, Ashgate, 2007, 118.

${ }^{36}$ Sobre esta cuestión J. L. Bermejo CABRero, Máximas, principios y símbolos politicos, Madrid, Centro de Estudios Constitucionales, 1986, 46.
} 
criados y no mas, aunque por su persona sea un angel». En definitiva, a nuestro juicio, en este punto el jesuita no está haciendo otra cosa que trasladar al gobierno eclesiástico aquello que iba a solicitar en su obra sobre la pedagogía real para el gobierno de la corona. En el primer capítulo del libro III del tratado, titulado «De los magistrados», Mariana pone de relieve la importancia que tienen las elecciones en los ministerios y demás empleos, pues de su integridad va a depender el prestigio de la corona. Por ello, sugiere el jesuita, se ha de examinar detenidamente quiénes han de ocupar dichos cargos; habida cuenta de la importancia de esta cuestión. Más concretamente, en relación al personal de palacio empleado considera que se ha de valorar la honradez, el ingenio, la prudencia (de nuevo, la prudencia), la grandeza de alma y la rectitud en la obediencia. El pueblo no puede tener en buena estima a quien que se rodea de personas entregadas a toda clase de vicios ${ }^{37}$. ¿Cómo conseguir la información que considera precisa el jesuita en este punto? Él mismo nos ofrece la respuesta. Según su parecer, será conveniente examinar la vida, costumbres e incluso el carácter de quienes se proponen para el servicio, antes llevar a cabo su admisión para acompañar o servir a la corona ${ }^{38}$.

Pues bien, como decimos, lo que hace Mariana en la carta que envía a su amigo es trasladar los principios que a grandes rasgos se acaban de exponer, contextualizados en el ámbito civil, al gobierno del arzobispado. Se trata para él de un asunto importantísimo, como así lo demuestra la reiteración de la idea en el documento. Por otra parte, también en este contexto muestra el religioso su negativa ante la inclusión de "seglares y mochachos"; una idea que a nuestro juicio, encontraría después reflejo -en el contexto de la Compañía de Jesús- en el Tratado de las cosas de la Compañia, donde el jesuita se quejaba de que se designaban para los cargos a personas menudas, con el fin de que llevasen a cabo lo que venía de Roma, fuera o no acertado ${ }^{39}$. A propósito de la cuestión que nos ocupa, Mariana sugiere al arzobispo que se acuerde «de lo que el arçobispo Miranda hizo en esta parte». Posiblemente se estuviera refiriendo en este punto a Fray Bartolomé Carranza de Miranda, arzobispo de Toledo, confesor de Felipe II ${ }^{40}$ que, según el criterio del jesuita, no habría escogido a las personas idóneas, y de ello se habrían

${ }^{37}$ J. De MARIANA, La dignidad..., 270 y 271. Sobre el papel de la prudencia en el reinado y en quienes aconsejan puede verse el estudio de H. E. BraUn, Juan de Mariana..., 118.

38 J. DE MARIANA, La dignidad..., 273.

39 J. DE MARIANA, «Discurso...», 606.

40 J. F. De La Peña y F. Fernández lanza, Personajes ilustres de la Universidad de Alcalá, Alcalá de Henares, Universidad de Alcalá, Servicio de Publicaciones, 1996, 29 y 30. 
derivado consecuencias indeseadas. Según Nogueira, que confirma la referencia al arzobispo Miranda en ese punto, cuando Mariana se está refiriendo a no tener personas dignas de confianza, estaba pensando en el cardenal Quiroga ${ }^{41}$. De ser acertada esta interpretación, quizá podría pensarse que en este punto el jesuita podría haber tenido en cuenta el trabajo llevado a cabo por aquel cardenal, que debió conocer de primera mano cuando colaboró con él en algunos trabajos relacionados con los índices de libros prohibidos ${ }^{42}$. El jesuita, sin embargo, no va más allá en este punto. Quizá pudiera estar pensando en el proceso por herejía por el que pasó Miranda, acusado de luteranismo (resultado de no haber contado con personas como Quiroga, cabría suponer, si seguimos el argumento anterior), o bien se estaba refiriendo a la conflictiva situación del arzobispado durante la ausencia del prelado. A propósito de esta última opción, quizá sea interesante recordar que, tras la detención del arzobispo, Felipe II designó a eclesiásticos de poco rango para gobernar la diócesis y convocó un concilio provincial para que emitiera recomendaciones. Sin embargo, el cabildo de la catedral toledana bloqueó el trabajo del concilio ${ }^{43}$. Si se acepta que fue precisamente este punto el que suscitó la crítica de Mariana, con ello debería aceptarse también que en el parecer del jesuita subyace un reproche implícito a Felipe II (que fue quien realizó las designaciones). Ello quizá pudiera considerarse no muy creíble, en atención a las declaraciones positivas que el jesuita dedicó al monarca en algunas de sus obras, pero la reflexión podría ser considerable, si se lleva a cabo un estudio más pausado de algunas de sus declaraciones ${ }^{44}$.

En nuestra opinión, las ideas de Mariana recogidas en la carta podrían considerarse manifestaciones de una propuesta para reformar el gobierno eclesiástico, que el jesuita pretendía inculcar a García de Loaysa; una aportación al proyecto de cambio que, no obstante, como ya hemos adelantado, aquel ya había iniciado en los años precedentes como gobernador. Según Pisa, se esperaban grandes bienes de él, así como la reforma de la situación eclesiástica y del arzobispado más concretamente ${ }^{45}$. No hay duda

\footnotetext{
41 A. NogueIRA, «Historia de la vida...», LV.

42 Index et catalogvs probibitorum, mandato Illustriss. Ac Reuerẽdiss. D. D. Gasparis A Qviroga, Cardinalis Archiepiscopi Toletani, ac in gregnis Hispaniarum Generalis Inquisitoris, denuò editus, Madriti, Apud Alphonsim Gomezium Regium Typographum, 1583; Index Librorvm expurgatorum, Illustrissimi ac Reuerendis. D. D. Gasparis Qviroga, Cardinalis \& Archiep. Toletani Hispan. Generalis Inquisitoris iussu editus, Madriti, Apud Alfonsum Gomezium Regium Typographum, 1584.

${ }^{43}$ R. L. KAGAN, «La Toledo del Greco», 55.

44 Sobre esta cuestión F. CENTENERA SÁNCHEZ-SECO, El tiranicidio..., 360, 361.

${ }^{45}$ F. DE PISA, Descripción..., 273 (segunda plana de la hoja).
} 
de que se trataba de una serie de intenciones cuyo origen ha de encontrarse en las pretensiones de la Contrarreforma y que ya pueden observarse en arzobispados anteriores. Por las circunstancias anteriormente señaladas, Miranda había dejado una diócesis sin reformar. No obstante, Quiroga, arzobispo desde 1577, afrontó aquella situación haciendo lo posible por adaptar las ceremonias y oficios a lo establecido en Trento. Así, por ejemplo, trató de eliminar de los oficios de la Iglesia cualquier aspecto secular o profano ${ }^{46}$. García de Loaysa debía ser el siguiente paso en aquella labor de cambio, al menos así lo debió entender Mariana. Cuando se refiere a la forma en la que el arzobispo debería llevar su casa, le recomienda que fuera honrada y grande, pero también «muy ecclesiastica y reformada». De esta manera, el escritor se presenta como un eslabón más de la Contrarreforma, bisagra entre dos arzobispados, en el que posiblemente fuera principal enclave del catolicismo en la época, después de Roma.

Antes de concluir el análisis del documento que nos ha venido ocupando, quisiéramos señalar que, en nuestra opinión, la racionalidad que subyace en los contenidos sobre el gobierno analizados encuentra reflejo en el plano formal. La letra con la que Mariana escribió la carta, aun con peculiaridades, resulta clara y se interpreta bien. Se trata de un texto equilibrado en cuanto al tamaño de letra y espacio interlineal, redactado con una letra cursiva, caracterizada por aspectos tales como la 'a' cerrada, la 's' larga, o la correcta separación de palabras en general ${ }^{47}$. Todas estas características son propias de la escritura humanística inclinada o cursiva, una categoría en la que, según pensamos, debería catalogarse el documento que nos ocupa. Este tipo de escritura constituye un reflejo de la racionalidad propia del movimiento humanista ${ }^{48}$ de la que, a nuestro juicio, participó el jesuita con las manifestaciones que acabamos de exponer.

\footnotetext{
46 R. L. KAGAN, «La Toledo del Greco», 55.

47 Sobre ello E. RUIZ GARCíA, «La escritura humanística y los tipos gráficos derivados», en A. Riesco Terrero (ed.), Introducción a la paleografía y la diplomatura general, Madrid, Editorial Síntesis, 1999, 170. En relación a la cuestión de la separación de las palabras que, no obstante, no en todo caso se da en el manuscrito que nos ocupa, conviene señalar que en ocasiones las letras de las palabras tienden a unirse, generando nexos mínimos. Ello, sin embargo, no es obstáculo para la lectura. Sobre esta cuestión J. C. GALENDE DÍAZ, «La escritura humanística en la Europa del Renacimiento», Espacio, Tiempo y Forma, Serie III, H. ${ }^{a}$ Medieval, 11 (1998), 212. Consultado en: http://espacio.uned.es/fez/eserv.php? pid=bibliuned:ETF985FEFDC-404B-0145-D745-FC7953B6C6A2\&dsID=Documento.pdf. Fecha de consulta: 02/11/2014.

48 Sobre ello E. RUIZ GARCíA, «La escritura humanística...», 170.
} 
El $\mathrm{p}^{\mathrm{e} 49}$ Sebastián $[\mathrm{Frz}]^{50}$, en una de los .4. del presente me escriuio de parte de V.S.I. hablase aquel criado sobre cierta conuersacion de que resultaua escandalo. Yo lo hize conel cuidado que era raçón, y conel mejor termino que supe. El lo niega y se escusa, y acusa otros como es ordinario. Quedamos que escriuiese a V.S.I. sus descargos: y promete que si no parecieren tales, hara puntualmente y con effecto todo lo que V.S.I. le manda. A mi dado que antes no sabia nada, y que podria ser falso lo que se le imputa, todauia me parece que es negocio que pide remedio. $\mathrm{Y}$ en verdad me he alegrado mucho que V.S.I. comiençe por los de su casa: y que por uno entiendanlos demas el recato que todos deuen tener. $\mathrm{Y}$ es aueriguado que tal sera el gouierno de un prelado quales fueren sus ministros y criados y no mas, aunque por su persona sea un angel. Por esto aunque sea atreuimiento deseo mucho que V.S.I. ponga los ojos en que la casa sea muy honrada y grande, como de tal prelado, pero juntamente muy ecclesiastica y reformada: Lo qual no podra ser si cargande muchos seglares y mochachos. Acuerdese V.S.I. de lo que el arçobispo Miranda hizo en esta parte, que en fin no se puede negar sino que tuuo cosas muy buenas: y de lo que padecio el buen nombrede lpasado por no tener a su lado personas tales. Y enestos principios es muy importante entablarse bien, para ganar las uoluntades de todos chicos y grandes: pues al prelado no es menos necesario esto y el credito en todo, para hazer buenos effectos, que al mercader para sus ganancias. Y es bien que V.S.I. sepa que no todos an tomado de una misma manera esta election. La causa principal debe ser la enbidia y pesarles a algunos que V.S.I. se les adelante tanto: pero junto conesto sera bien mirar si ay alguna otra cosa en que se repare, y procurar que en todo sea tanto mayor el recato. Torno a dezir que el pontificado de V.S.I. sera tal, quales fueren los criados y ministros y no mas. Este es el parabien que yo doy a V.S.I. una grande esperança que tengo de que V.S.I. sera uno de los mas exemplares prelados que de muchos años aca esta silla aya tenido. Lo cual haga nuestro $\mathrm{S}^{\mathrm{r} 51}$ como todos deseamos y su Yglesia a menester. No ${ }^{\text {me }}$ ofrezco a [seruir $\left.{ }^{52}\right]$ con mi cornadillo, pues esta claro que no tengo de faltar a tantas obligaciones, dado que los uiejos no somos ya de provecho sino para gruñir y murmurar. Dios $g^{\mathrm{e} 53}$ a V.S.I. por largos años.

De Toledo y de Julio .7. de 1598.

\footnotetext{
49 Entendemos 'padre'.

50 Según Nogueira 'Fernandez'.

51 Entendemos 'Señor'.

52 Según Nogueira.

53 Entendemos 'guarde'.
} 
Jn' de Mariana $\mathrm{SJ}^{54}$

\section{Más cuestiones de gobierno y otras intelectuales}

La carta fechada el 7 de julio de 1598 obtuvo respuesta del arzobispo algunos días después. En esta ocasión nos encontramos con un documento en el que aparece un estilo de letra más manierista, propio de la escritura bastarda caracterizada, por ejemplo, por letras más redondeadas ${ }^{55}$. Tal disposición dificulta más la interpretación ${ }^{56}$, y así quedará patente en la transcripción que presentamos más adelante. Sin embargo, más allá de los pormenores que pudieran apuntarse desde un punto de vista formal, nos interesa referirnos a este aspecto porque en él, probablemente debiera verse el reflejo de un estatus social. En este sentido, conviene tener en cuenta que el tipo de letra señalado se utilizaba por la clase privilegiada ${ }^{57}$, y que García de Loaysa formaba parte de aquella en el plano eclesiástico. A propósito de ello, resulta muy interesante comparar esta circunstancia con los aspectos formales considerados en el apartado anterior. Con la letra humanística cursiva Mariana se sitúa formalmente en un plano diferente. En este sentido, puede resultar significativo el dato de que dicho tipo de letra fue el que se usaba comúnmente en España desde los inicios del siglo XVI58.

En la carta que ahora nos ocupa, el arzobispo comienza refiriéndose al documento analizado en el apartado anterior diciendo «Herecibido la deV.P. de .8. deste». Como vemos, utiliza la sigla "V.P.". Algunos de los significados que atribuye Álbarez Braña a aquella, en su relación de siglas son vicarius praefecti, urbis praefectus o vir probus, prudens, perfectissimus, etc. ${ }^{59}$ En nuestra opinión, no obstante, ninguno de estos significados es aplicable al caso que nos ocupa, bien porque hacen referencia a cargos de la administración romana (en los dos primeros casos) ${ }^{60}$, bien porque no nos encontramos

\footnotetext{
$54 \mathrm{La}$ 'J' sobre la 'S'.

55 Sobre ello E. RuIZ GARCÍA, «La escritura humanística...», 172, 173.

56 [G. DE ANDRÉS según algunas fuentes], Apuntes de paleografía y diplomática para uso de los alumnos de la cátedra, Madrid, Universidad Complutense, 1981 (sin publicar), 191.

${ }^{57}$ Sobre ello E. RUIZ GARCíA, E., "La escritura humanística...”, 174.

58 [G. DE ANDRÉS], Apuntes de paleografía, 30.

59 R. ÁlvarEZ DE LA BRAÑA, Siglas y abreviaturas latinas con su significado por orden alfabético y de un catálogo de abreviaturas, New York, Georg Olms Verlag, 1978, 173.

60 Puede verse, por ejemplo, W. W. BuCKLAND, A Text-Book of Roman Law, New York, Cambridge University Press, third edition, 2007, 52.
} 
ante fórmulas de tratamiento. El análisis de otros documentos de la época nos lleva a pensar que el significado que hemos de atribuir a la sigla es el de "vuestra paternidad"61.

$\mathrm{Al}$ menos en parte, la respuesta que dejó el arzobispo en el documento que nos ocupa, pudiera entenderse como una muestra de agradecimiento ante los consejos relativos al gobierno eclesiástico que le había sugerido el jesuita. La primera parte de la carta, que se desarrolla en esta línea, recoge la siguiente declaración: «con ella muy gran [contento], por los buenos consejos $\tilde{q}$ me da, que si no es con ellos nada sepuede acertar». No obstante, el prelado va más allá de los agradecimientos, para solicitar al destinatario ayuda en lo que concierne a la designación o remoción de personas que han de ocupar los cargos. Hemos de entender que se estaba refiriendo a los del arzobispado, como así lo demuestran las siguientes concreciones. García de Loaysa se refiere a la elección de los ministros, encomendándose a Dios para acertar en esta tarea, aunque poco después parece referirse también a personal para su compañía. En la carta podemos leer «assi para las cosas $\tilde{q}$ se pueden ofrecer como para mi compañia». En este último punto, pensamos que el arzobispo estaba pensando en las personas que habrían de componer su servicio personal, es decir, lo que se denominaba familia. Pero además, entendemos que García de Loaysa podría haber solicitado también ayuda al jesuita para la formación de la curia. Quizá pensaba en ella cuando se refería a la elección de ministros. La curia estaba compuesta por vicarías, obispados auxiliares y otros cargos. A propósito de este colectivo, no debe olvidarse la complejidad que comprendía el arzobispado, a la que nos referimos anteriormente, una circunstancia que debió hacer ineludible la delegación de funciones ${ }^{62}$.

La segunda parte de la carta recoge cuestiones de carácter intelectual aunque, como señalaremos más adelante, su razón de ser se encuentra también en conexión con los propósitos de reforma para el gobierno eclesiástico. Se trata de comentarios sobre algunas obras. Según pensamos, los intercambios de información de este tipo probablemente fueron frecuentes en la relación mantenida por remitente y destinatario a lo largo de los años. El hecho de que Mariana interviniera de diferentes formas en varios

${ }^{61}$ A modo de ejemplo, puede consultarse TereSA DE JEsús, «Cartas», en Escritos de Santa Teresa, t. II, Madrid, M. Rivadeneyra, 1862, pp. 114-117.

${ }^{62}$ Sobre estas cuestiones A. ARTOLA RENEDO, «El patrocinio intraclerical en el Antiguo Régimen: curias y familias episcopales de los arzobispos de Toledo (1755-1823)», REDES-Revista hispana para el análisis de redes sociales, 21/6 (2011), 4 y ss. Consultado en: http://revista-redes.rediris.es/pdf-vol21/vol21 6.pdf. Fecha de consulta: 02/11/2014. 
proyectos, de los que también formó parte el arzobispo, ofrece fundamentos para esta presunción. La colaboración con García de Loaysa no sólo se advierte en la gestación del tratado De rege et regis institutione. También se puede apreciar, por ejemplo, en el trabajo decisivo que llevó a cabo el jesuita para sacar adelante el Manual para la Administración de los Sacramentos ${ }^{63}$; y en su participación en una edición de las obras de San Isidoro ${ }^{64}$, un proyecto del que también formó parte el que después sería arzobispo de Toledo ${ }^{65}$.

A propósito de la noticia en la que ahora nos detenemos, debe señalarse también que García de Loaysa tenía una gran afición por la lectura. Así lo demuestra la gran biblioteca personal que consiguió, compuesta de unos 3.000 volúmenes ${ }^{66}$. Quizá los recursos que nombra en la carta pertenecieran a dicho fondo. El prelado aporta dos nombres, Justo y Gregorio, aunque apenas ofrece datos sobre ellos, ni tampoco títulos suficientemente explícitos de obras (algo lógico, teniendo en cuenta que el remitente sabría sin duda que su destinatario conocía el material al que se estaba refiriendo). Sin embargo, ciertos detalles que aparecen en el documento nos ofrecen la posibilidad de, al menos, bosquejar algunas aproximaciones. Por una parte, nos encontramos con que García de Loaysa da a entender que el trabajo de Justo se encontraba impreso en Urgel. Ello nos invita a pensar que se estaba refiriendo a Justo, el obispo de Urgel, hermano de Justiniano, obispo de Valencia. De él nos cuenta Isidoro de Sevilla, en su Liber de wiris illustribus, que editó un libro breve y con sentido alegórico, dedicado al Cantar de los Cantares $^{67}$. Esta noticia es bastante relevante para nuestros intereses, pues García de Loaysa se refiere en la carta que nos ocupa a «Vn libro de mano antiguo, en $\tilde{\mathrm{q}}$ auia algunos opusculos de Justo sobre los cantares». Hemos de entender, por tanto, que el arzobispo se estaba refiriendo a la obra de la que da noticia Isidoro de Sevilla, cuyo título original fue In cantica canticorum explicatio mystica ${ }^{68}$. Como hemos visto, la noticia que presenta García de Loaysa parece dar a entender que se trataba de una obra en la que se

\footnotetext{
63 M. BAllesteros GAiBrois, El padre Juan de Mariana. La vida de un sabio. Barcelona, Editorial Almatea, 1944, 56 y 57.

${ }^{64}$ DIVI ISIDORI, Opera, tomo I, pars altera, Madriti, ex Typographia Regia, 1599.

65 M. BALleSteros GAiBrois, El padre Juan de Mariana, 80.

66 A. FERnÁndez COLLADO, La catedral de Toledo..., 79 y 255.

67 ISIDORVS HISPALENSIS EPISCOPVS, «Liber de uiris illustribus», en C. CODOÑER, El -De viris illvstribvsde Isidoro de Sevilla, Salamanca, Consejo Superior de Investigaciones Científicas, Instituto "Antonio de Nebrija”, 1964, 145.

68 S. IRANZO ABELLÁN, «Justo de Urgel», en C. Codoñer (coord.), La Hispania visigótica y mozárabe. Dos épocas en su literatura, Salamanca, Ediciones Universidad de Salamanca, 2010, 61.
} 
recogía la aportación de Justo señalada, pero también otras (se refiere a "algunos opúsculos”). En realidad, en nuestra opinión aquellas otras aportaciones podrían haber sido los documentos que encabezaban la obra en cuestión: dos cartas y un prólogo ${ }^{69}$. La información pensamos que podría haber resultado interesante para Mariana, dado que Justo utilizó las citas bíblicas de la Vulgata70, y el jesuita también demostraría su interés por aquella en diversas ocasiones a lo largo de su vida. Prueba de ello ofrecen el dictamen que emitió en relación a la Biblia políglota de Arias Montano (hacia 1577), donde echa en falta un mayor cuidado por defender la Vulgata ${ }^{71}$, o uno de los opúsculos de los Tractatus VII titulado Pro editione Vulgata ${ }^{72}$.

En lo referente al otro autor que se nombra en el manuscrito, creemos que se trata del Papa Gregorio Magno. Fundamentamos esta hipótesis en los siguientes datos que tomamos del documento. A García de Loaysa le resultaba copiosa la obra de un autor al que se refiere con el nombre de Gregorio, advierte en ella «los sentidos spirituales, allegoricos, y anagogicos», y considera que el trabajo en cuestión trata poco el literal y el moral algo más. Éstas podrían ser, en líneas generales, algunas de las características del trabajo Moralia in $\mathrm{Job}^{73}$; una obra que consta de treinta y cinco libros y que, según una voz experta en la cuestión, es ajena a cualquier tentativa de sistematización. Dichas características son ya indicio de un trabajo extenso y quizá excesivo. Además -seguimos al testimonio experto-, si bien Gregorio atribuye al principio de su obra importancia al sentido literal (entendemos que se trata de una forma de interpretación), a partir del quinto libro priman casi exclusivamente los sentidos alegórico y místico (ambos contribuyen a la elaboración de un sentido espiritual) ${ }^{74}$. Esta complejidad probablemente pueda explicarse si se tiene en cuenta que estamos ante un trabajo dedicado a una audiencia monacal ${ }^{75}$. Como puede observarse, el examen expuesto

\footnotetext{
${ }^{69}$ Ibidem.

70 Ibidem.

${ }^{71}$ Sobre la cuestión puede verse, por ejemplo, una carta que anuncia el envío de la censura, y que se transcribe en G. CIROT, Mariana..., 399, 400.

72 I. MARIANAE, «Pro editione vulgata», Tractatus VII, Coloniae Agrippinae, Antonij Hierati, 1609, 33126.

73 Gregoire Le Grand, Morales sur Job, première partie, livres I et II, Paris, Les Éditions du Cerf, troisième edition revue et corrigée, 1989.

74 R. GILLET, «Introduction», en GREGOIRE LE GRAND, Morales sur Job, première partie, livres I et II, Paris, Les Éditions du Cerf, troisième edition revue et corrigée, 1989, 11-13.

75 R. LAHAM COHEN, «En torno a motivaciones y efectos del discurso antijudío: El caso de los Moralia in Iob de Gregorio Magno», POLIS. Revista de ideas y formas politicas de la Antigüedad Clásica, 23 (2011), 116.
} 
se asemeja bastante a las percepciones que ofrece García de Loaysa. A propósito de la noticia del prelado, incluso nos aventuramos a pensar que probablemente estaba informando a Mariana del texto que estaba leyendo en el prólogo de la obra Moralia in $J o b$, donde se recoge lo siguiente: «E toda la ordenança delas palabras diuinales por rrazondestas quatro maneras es departida e esto es por entendimiento istorial o allegorico o moral o otra manera que es dicha anagógica» ${ }^{76}$.

El remitente también señala que había hecho 'trasladar' los textos que comenta. Concretamente, dice lo siguiente: «Antes q̃saliesse de $\mathrm{Ma}^{\mathrm{d}}$, auia començado auerVn libro de mano antiguo, en $\tilde{q}$ auia algunos opusculos, de Justo sobre los cantares, y de Gregorio el liberitano, sobre lo mismo [.] he los echo trasladar». Posiblemente con ello se estaba refiriendo a un cambio de lugar. Otra opción, menos probable, sería entender que García de Loaysa da noticia de la traducción de las obras, pero ¿a qué lengua? Siendo ambas de origen latino ${ }^{77}$, hemos de entender que la traducción, de haber existido, habría sido al castellano. Como decimos, no obstante, esta opción no parece tener mucho sentido. Los Moralia in Job, por ejemplo, ya habían sido traducidos, según la crítica general, por Pero López de Ayala ${ }^{78}$. Es cierto, no obstante, que podrían aportarse datos para sustentar la hipótesis de posibles traducciones. Por una parte, en lo que respecta a la primera obra citada, resulta curioso comprobar que en un estudio introductorio de Chao a una de las ediciones de la Historia de España, se descubre entre la relación de obras de Mariana una traducción al Cántico de los cánticos ${ }^{79}$. Sin embargo, este trabajo se atribuye a Mariana y se enmarca cronológicamente en la última etapa de su vida (recordemos que muere en 1624, y que la carta que nos ocupa data de 1598). Por otra parte, es cierto que además de la

Consultado en: $\quad$ http://dspace.uah.es/dspace/bitstream/handle/10017/19642/ 115151 motivaciones LahamPOLIS 2011 N23.pdf?sequence $=1$ \&is Allowed $=\mathrm{y}$. Fecha de consulta: 10/11/2014.

${ }^{76}$ Reproducido en J. H. FUENTES, «El primer prólogo a los Morales de San Gregorio de Pero López de Ayala», Incipit, XXX (2010), 6 y 7. Consultado en: http://www.academia.edu/3774565/ El_primer_pr\%C3\%B3logo_a los_Morales_de_San_Gregorio_de_Pero_L\%C3\%B3pez de_Ayala.

Fecha de consulta: 10/11/2014.

77 Ver sobre esta cuestión, por ejemplo, las consideraciones de J. M. ESCOLÀ TUSET, «El latín del obispo Justo de Urgell», en C. Arias Abellán (ed.), Latin vulgaire-Latin tardif. VII. Actes du VII'ème Colloque international sur le latin vulgaire et tardif. Séville, 2-6 septembre 2003, Sevilla, Universidad de Sevilla, 2006, 243252; y la versión bilingüe de la obra de Gregorio el Magno en GregoIre LE Grand, Morales sur Job.

${ }^{78} \mathrm{~J}$. H. Fuentes, «El primer prólogo...», 1; G. AvENOZA, «Traducciones, público y mercenazgo en Castilla (siglo XV)», Romania, 128 (2010), 456. Consultado en: http://www.academia.edu/3609720/ Traducciones_p\%C3\%BAblico_y mecenazgo_Castilla siglo_XV. Fecha de consulta: 10/11/2014.

${ }^{79}$ E. ChaO, «Juan de Mariana», en J. De MARIANA, Historia General de España. La compuesta, enmendada y añadida por el Padre Mariana, Madrid, Imprenta y Librería de Gaspar y Roig, 1849, X. 
traducción de López de Ayala a la que antes nos referíamos, existe también noticia de otra traducción anónima de los Moralia in Job, que se ha transmitido por los manuscritos de El Escorial, y que al menos uno de ellos, el manuscrito Esc. b.ii.12, coincide con la labor realizada por López de Ayala ${ }^{80}$. Esta información invita a recobrar la hipótesis de que el arzobispo pudiera haberse referido a una traducción que mandó realizar (como después veremos, García de Loaysa firmó la carta en San Lorenzo del Escorial). Sin embargo, de nuevo habría que poner en cuestión esta idea, si tenemos en cuenta que la traducción en cuestión, recogida en un manuscrito de El Escorial, se debió llevar a cabo hacia el primer cuarto del siglo $\mathrm{XV}^{81}$.

Según podemos deducir del contenido de la carta, García de Loaysa debió enviar ambas obras a Mariana, con el fin de que le diera su parecer en relación a una futura impresión de aquellas. Sus palabras son las siguientes: «despues $\tilde{q}$ V. P. los ayaVisto Veremos si conuiene imprimillos». De nuevo, pensamos que esta intención debió formar parte de los planes reformadores de García de Loaysa. En este sentido, no debe perderse de vista la importante carga exegética que tienen las dos obras consideradas.

En la última parte del documento, el remitente se refiere a 'López', quizá se tratase de la persona con la que Mariana había ejercido de mediador, en el asunto al que se hacía referencia en la carta anterior. No podemos acabar este apartado sin antes hacer referencia al sorprendente final del manuscrito. Si la interpretación que se va a reproducir es acertada en este punto, se puede afirmar que estamos ante una noticia que informa de la salud de Felipe II. «Su Mgd esta mejor, gras adiós», señala García de Loaysa. El sentido común invita a pensar que podría haberse tratado de una leve mejoría del rey. Sin embargo, aquella no debió ser suficiente para que el monarca presenciase fuera de su lecho la ceremonia de consagración de García de Loaysa ${ }^{82}$. Dos meses después de que el arzobispo escribiese a Mariana, Felipe II falleció. Fue un domingo, 13 de septiembre, a las 5 de la mañana. Algunos días antes (el 1 de septiembre), García de Loaysa le

${ }^{80}$ G. AvenOZA, «Traducciones...(®), 456, L. SERRANO, «Traducción castellana de los morales de San Gregorio», Revista de archivos, bibliotecas y museos, 11-12 (1911), 395.

81 L. SERrano, «Traducción castellana...», 395, 396; G. AvenOZA, «Carta (correo electrónico)». Consultado en http://pb.lib.berkeley.edu/saxon/SaxonServlet?source=BETA/Display $/ 10466$ Work.xml\&style $=$ BETA/templates $/$ Work.xsl\&gobk $=\mathrm{http} \% 3 \mathrm{~A} \% 2 \mathrm{~F} \% 2 \mathrm{Fpb}$. lib.berkeley.edu $\% 2 \mathrm{Fxtf} \% 2 \mathrm{Fs}$ earch $\% 3 \mathrm{~F} \% 26$ everyone $\% 3 \mathrm{D} 1031 \% 26$ textjoin $\% 3 \mathrm{Dand} \% 26 \mathrm{rmode} \% 3 \mathrm{Dphilobeta} \% 26$ browseout $\% 3$ Dpers on $\% 26$ sort $\% 3$ Dauthor $\% 26$ startDoc $\% 3$ D1. Fecha de consulta: 23/10/2014.

82 A. FERNÁNDEZ COLLADO, La catedral de Toledo..., 256. 
administró la extremaunción ${ }^{83}$. La noticia en la que hemos reparado revela sin lugar a dudas el lugar en el que García de Loaysa escribió la carta: el monasterio de San Lorenzo del Escorial, donde murió Felipe II. El dato se confirma en el documento, cuando al final del texto puede leerse «en S Lor ${ }^{\mathrm{zo} \cdot » .}$

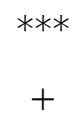

Herecibido la deV.P. de .8. deste, con ella muy gran $\left[\right.$ contento $^{84}$, por los buenos consejos $\tilde{\mathrm{q}}^{85}$ me da, que si no es con ellos nada sepuede acertar, yansi $\sup ^{\mathrm{co8} 6}$ aV.P. $\tilde{\mathrm{q}}$ todo lo quentendiere $\tilde{\mathrm{q}}$ conuiene me lo auise, por $\tilde{\mathrm{q}}$ mi deseo es bueno yesto puedo certificar aV.P. mas es menester qulos ministros lo sean, y yo lo procuro, y siempre he holgado con buenos, yansi fio en N. $\mathrm{S}^{\mathrm{r} 87}$, que me [ayudara ${ }^{88}$ ] a certar en las electiones, y si de los $\tilde{\mathrm{q}}$ ay ay sabe V.P. algo por donde no conuenga continuallos en los oficios lesup ${ }^{\text {co89 }}$ que con todo silencio, me lo auise, y si le ocurre algunas personas buenas, de letras yVirtu ${ }^{\mathrm{d} 90}$, me las diga / assi para las cosas q̃ se pueden ofrecer como para mi compañia / que no tengo mas intento de cumplir con el oficio que seme haen cargado, sin tener otro fin ni respeto a cosa humana, los principios son muy importantes, mas no pueden ser tan cumplidos, como lo que de ellos sale, digo esto, por la casa que [asin $\left.{ }^{91}\right]$ procuro $\tilde{q}$ sea de buenos [sugetos $^{92}$ ]

La $\operatorname{can}^{\mathrm{d} 93}$ con el tiempo ira creciendo, encomiendelo V.P. Todo a N. S ${ }^{\mathrm{r} .94}, \mathrm{y}$ siempremevaya [avisando ${ }^{95}$. Antes $\tilde{\mathrm{q}}$ saliesse de $\mathrm{Ma}^{\mathrm{d} 96}$, auia començado auerVn libro de mano antiguo, en $\tilde{q}$ auia algunos opusculos, de Justo sobre los cantares, y de Gregorio el liberitano, sobre lo mismo [.] he los echo trasladar, y lo de justo lo he revisto, y

${ }^{83}$ F. DE PISA, Descripción..., 271 (primera y segunda plana de la hoja); A. FERnÁndeZ Collado, La catedral de Toledo..., 256.

${ }^{84}$ Según Nogueira. En el original parece haber una abreviatura, que podría hacer referencia a 'merced'.

${ }^{85}$ Encima de esta letra aparece una especie de acento, que hemos interpretado como virgulilla.

${ }^{86}$ Entendemos 'suplico'.

${ }^{87}$ Entendemos 'Señor'.

${ }^{88}$ Según Nogueira.

${ }^{89}$ Entendemos «le suplico».

${ }^{90}$ Entendemos «y Virtud».

${ }^{91}$ Según Nogueira 'ahora'.

${ }^{92}$ Según Nogueira.

${ }^{93}$ Según Nogueira 'cantidad'.

${ }^{94}$ Entendemos 'Señor'.

${ }^{95}$ Según Nogueira. Pensamos que podría entenderse también «a informan».

${ }^{96}$ Entendemos 'Madrid'. 
[enbiare $^{97}$ ] aV.P. y aunq este tratado anda impreso, por de Vrgel yo pienso ques de Toledo, $\tilde{\mathrm{q}}$ así parece por algunas [conjeturas ${ }^{98}$ ] q̃V.P. Vera, aquí estoy mirando lo de Gregorio, es mas copioso, aunq̃ separecen harto en elstilo yen los sentidos spirituales, allegoricos, y anagogicos, $\tilde{\mathrm{q}}$ del literal poco tratan, del Moral mas auñ poco, despues $\tilde{\mathrm{q}} \mathrm{V}$. P. los ayaVisto Veremos si conuiene imprimillos.

en lo de López, le hescrito quhaga lo q̃ V.P. le diga, si[no quiere ${ }^{99}$ darme ocasion a que vse de muchos mas seueros, yV.P. lemande q̃no entre en aquella casa, o que soja ${ }^{100}$ aquella, o la más.

Su Mg ${ }^{\text {d101 }}$ esta mejor, gras ${ }^{102}$ adios q̃seaV.P. en S Lor ${ }^{\text {zo.103 }} 12$ dejullio 1598.

Garcia de Loaisa,

\footnotetext{
${ }^{97}$ Según Nogueira.

${ }^{98}$ Según Nogueira. Quizá podría decir 'coseduras'.

${ }^{99}$ Según Nogueira.

100 Según Nogueira 'escoja'.

${ }^{101}$ Entendemos 'Majestad'.

102 Entendemos 'gracias'.

103 Entendemos «San Lorenzo».
} 